\title{
A synthetic data set of high-spectral-resolution infrared spectra for the Arctic atmosphere
}

\author{
Christopher J. Cox ${ }^{1,2}$, Penny M. Rowe ${ }^{3,4}$, Steven P. Neshyba ${ }^{5}$, and Von P. Walden ${ }^{6}$ \\ ${ }^{1}$ Cooperative Institute for Research in Environmental Sciences, University of Colorado, Boulder, CO, USA \\ ${ }^{2}$ NOAA Earth System Research Laboratory, Physical Sciences Division, Boulder, CO, USA \\ ${ }^{3}$ NorthWest Research Associates, Redmond, WA, USA \\ ${ }^{4}$ Department of Physics, Universidad de Santiago de Chile, Santiago, Chile \\ ${ }^{5}$ Department of Chemistry, University of Puget Sound, Tacoma, WA, USA \\ ${ }^{6}$ Department of Civil and Environmental Engineering, Washington State University, Pullman, WA, USA
}

Correspondence to: Christopher J. Cox (christopher.j.cox@noaa.gov)

Received: 27 November 2015 - Published in Earth Syst. Sci. Data Discuss.: 18 January 2016

Revised: 12 April 2016 - Accepted: 15 April 2016 - Published: 12 May 2016

\begin{abstract}
Cloud microphysical and macrophysical properties are critical for understanding the role of clouds in climate. These properties are commonly retrieved from ground-based and satellite-based infrared remote sensing instruments. However, retrieval uncertainties are difficult to quantify without a standard for comparison. This is particularly true over the polar regions, where surface-based data for a cloud climatology are sparse, yet clouds represent a major source of uncertainty in weather and climate models. We describe a synthetic high-spectralresolution infrared data set that is designed to facilitate validation and development of cloud retrieval algorithms for surface- and satellite-based remote sensing instruments. Since the data set is calculated using pre-defined cloudy atmospheres, the properties of the cloud and atmospheric state are known a priori. The atmospheric state used for the simulations is drawn from radiosonde measurements made at the North Slope of Alaska (NSA) Atmospheric Radiation Measurement (ARM) site at Barrow, Alaska $\left(71.325^{\circ} \mathrm{N}, 156.615^{\circ} \mathrm{W}\right)$, a location that is generally representative of the western Arctic. The cloud properties for each simulation are selected from statistical distributions derived from past field measurements. Upwelling (at $60 \mathrm{~km}$ ) and downwelling (at the surface) infrared spectra are simulated for 260 cloudy cases from 50 to $3000 \mathrm{~cm}^{-1}$ (3.3 to $200 \mu \mathrm{m}$ ) at monochromatic (line-by-line) resolution at a spacing of $\sim 0.01 \mathrm{~cm}^{-1}$ using the Line-by-line Radiative Transfer Model (LBLRTM) and the discrete-ordinate-method radiative transfer code (DISORT). These spectra are freely available for interested researchers from the NSF Arctic Data Center data repository (doi:10.5065/D61J97TT).
\end{abstract}

\section{Introduction}

Cloud properties, including height, temperature, particle size, and thermodynamic phase modulate precipitation development, cloud lifetime, and cloud radiative forcing. In climate change scenarios, models show that radiative forcing by Arctic clouds amplifies greenhouse warming, with the largest model errors in winter and spring, when longwave warming dominates (Vavrus et al., 2009). Thus, an accurate understanding of the radiative effects of Arctic clouds, as well as quality estimates of observed cloud properties, is needed to advance research focused on the role of clouds in climate and to support modeling applications at many scales.

In the polar regions, progress toward this goal is hampered by limited data, large uncertainties, and systematic biases in different remote sensing approaches to retrieving cloud properties. Passive infrared sensors are well suited to examine the interplay between clouds and infrared radiation because they measure infrared radiation directly and can be used to retrieve cloud properties. Passive infrared sensors have been used to retrieve cloud properties from satellite platforms, providing broad spatial coverage (e.g., Strabala et al., 1994; 
Baum et al., 2000; Li et al., 2005; Wang and Key, 2005; Kay and Gettelman, 2009; Kahn et al., 2014), as well as from surface observatories, providing high temporal resolution (e.g., Rathke et al., 2002a, b; Turner et al., 2003; Turner, 2005; Zhao et al., 2012; Garrett and Zhao, 2013; Cox et al., 2014). But because retrieval algorithms based on these sensors include radiative-equivalent assumptions particular to the infrared part of the spectrum, the retrieved cloud properties do not always agree with results obtained from other types of sensors: they are most sensitive to optically thin clouds near the instrument (i.e., high clouds for satellite-based sensors and low clouds for surface-based sensors), typically are layer-averaged through all cloud columns, and generally are more sensitive to liquid than ice, primarily due to how differences in the geometries of ice and liquid hydrometeors affect their infrared radiance (e.g., Garrett and Zhao, 2006). Numerous intercomparison studies report systematic differences between cloud properties retrieved from infrared sensors and results from other sensors (e.g., Shupe et al., 2008; Dong et al., 2008; Karlsson and Dybbroe, 2010; Liu et al., 2010; Minnis et al., 2011; Vogelmann et al., 2012; Zhao et al., 2012; Chan and Comiso, 2013; Jin and Nasiri, 2014).

Biases are difficult to reconcile when working with real data alone. In large part, this is due to fundamental differences in perspective and measurement sensitivity between different sensor types: some instruments record cloud properties on a timescale that is fast compared to the timescale of cloud evolution, for example, while others yield average properties. A similar situation arises due to variations in field of view. Even within the set of infrared remote sensing algorithms currently in use, comparative evaluation of different algorithms is often not possible because the actual cloud properties are not known.

Thus, alternative evaluation approaches (e.g., Bugliaro et al., 2011; Pincus et al., 2012) are needed to complement conventional techniques to better constrain biases, facilitate algorithm development, and advance interpretation of results. Simulated data sets, though idealized, reduce the number of sources of uncertainty, thereby permitting a more detailed evaluation of many aspects of individual methodologies and measurement sensitivities. In a simulated data set, the properties of interest are known a priori and the assumptions associated with the data set are controlled. Considerations for the design of such a data set rely on which assumptions to control so as to isolate the effects of others; thus, the design of the data set is ideally customized to address the questions of interest to a particular study and may include various combinations of simplifications and realistic aspects.

In this manuscript, we describe a simulated data set that can be used to represent a cloud climatology for the Arctic as viewed from the surface or space by passive infrared sensors. A base data set is provided that has simplified cloud properties, including spherical ice particles and vertically homogeneous cloud properties, for a variety of realistic atmospheric profiles, cloud heights, phase partitioning, optical depths, and effective radii characteristic of the Arctic. The simplifications of the modeled clouds allow for many of the fundamental aspects of retrieval algorithms (such as the ability to distinguish phase without relying on particle size) and input data (such as spectral resolution and noise) to be analyzed in the presence of a limited number of uncertainty sources. To allow the data set to be used to determine the effects of ice habit and vertical cloud inhomogeneity on retrievals, additional simulations are included that are identical except in varying these attributes.

The data set is applicable to studies focusing on assessing uncertainties in cloud properties derived from hyperspectral and narrow-band infrared radiances, which currently represent a substantial source of data for the Arctic. The inclusion of a wide range of cloud properties is useful for such studies, as well as making the data set useful for studies focused on the infrared radiative effects of Arctic clouds.

The data set described here is based on atmospheric profiles measured by radiosoundings from Barrow, Alaska $\left(71.325^{\circ} \mathrm{N}, 156.615^{\circ} \mathrm{W} ; 8 \mathrm{~m}\right)$, a location thought to be generally representative of the far-western Arctic atmosphere (Dong and Mace, 2003; Dong et al., 2010; Shupe et al., 2011; Cox et al., 2012). Because the data set is intended to be representative of the Arctic in general, it is only loosely based on Barrow; the main objective is to encompass the range of properties expected in the Arctic. Cloud properties are generalized from results reported for the western Arctic and Canadian Archipelago regions (Shupe et al., 2011; Shupe, 2011; Cox et al., 2014). The data set consists of infrared radiative transfer calculations of 260 unique "cloudy-sky" cases comprised of a base set of 222 simplistic cases (homogeneous, mixed-phase clouds with ice modeled as spheres) and 38 more complex cases (e.g. non-homogeneous clouds and clouds with varying ice habits). The simulations are based on varying cloud properties for 30 unique atmospheric states (e.g., temperature, humidity, and $\mathrm{CO}_{2}$ profiles) that are representative of scenes containing clouds. The spectral range is 50 to $3000 \mathrm{~cm}^{-1}(200-3.3 \mu \mathrm{m})$ at monochromatic, or lineby-line resolution, spaced at $\sim 0.01 \mathrm{~cm}^{-1}$. Through convolution of the simulated spectra with an instrument response function (e.g., Beer, 1992), the data set can be customized to mimic data acquired by a range of instrumentation. The data set is available for community use; data access information is provided in Sect. 6 .

\section{Radiative transfer models}

To simulate upwelling and downwelling infrared spectra, two radiative transfer models are used. The Line-By-Line Radiative Transfer Model (LBLRTM), version 12.2 (Clough et al., 1992, 2005), is used initially to calculate vertical profiles of infrared optical depths of radiatively active gases under clear-sky conditions. LBLRTM has been validated ex- 
tensively (e.g., Clough et al., 1992, 2005; Delamere, 2010; Alvarado et al., 2013).

LBLRTM requires vertical profiles of temperature and radiatively active gases (e.g., water vapor, carbon dioxide, and ozone) as input to simulate clear-sky optical depth profiles and radiance. Preparation of the profiles is described in Sect. 3.1. The LBLRTM calculations were performed line by line from 50 to $3000 \mathrm{~cm}^{-1}(3.3-200 \mu \mathrm{m})$ using the 2008 version of the high-resolution transmission molecular absorption database (HITRAN) (Rothman et al., 2009). The gaseous optical depth profiles are then used together with cloud properties as input to a program for calculating discrete-ordinate-method radiative transfer in scattering and emitting layered media (DISORT) (Stamnes et al., 1988, 2000) to simulate cloudy-sky spectra. For this data set, only single-layered clouds were calculated. Both DISORT and LBLRTM simulate radiation in a plane-parallel model atmosphere.

DISORT performs radiative transfer at a given wavenumber and requires a variety of input parameters. (Even though DISORT is monochromatic, a small wavenumber interval is specified for calculation of the Planck radiation.) A Matlab code ("runDisort.m" available at https://github.com/ prowe12/runDisort_mat) was developed for organizing the inputs, running DISORT at each wavenumber to calculate the infrared radiance at the surface or top of the atmosphere, and combining the radiances into a high-resolution spectrum. Inputs to runDisort.m include wavenumber, gaseous optical depths (e.g., from LBLRTM), and the temperature profile, as well as the cloud properties (cloud layer, visible optical depths, and effective radii for liquid and ice). Additional inputs are as follows. For downwelling spectra, the viewing angle is set to $0^{\circ}$ relative to zenith, while for upwelling the viewing angle is $180^{\circ}$. The solar zenith angle is calculated for a particular date and location, where the chosen dates represent all four seasons (see Sect. 3.1) and the location was chosen in the Canadian Arctic at $\sim 80^{\circ} \mathrm{N}, 86^{\circ} \mathrm{W}$. Thus, solar angles are typically low (note that, for wavenumbers smaller than about $2000 \mathrm{~cm}^{-1}$, the influence of solar radiation is small). The surface type is set to Lambertian, and the surface albedo is determined from the surface emissivity measurements for ice/snow from the Moderate Resolution Imaging Spectrometer (MODIS) University of California, Santa Barbara (UCSB), emissivity library. Beyond the wavenumber range of the emissivity library $\left(687-998 \mathrm{~cm}^{-1}\right)$, the emissivity is assumed to be spectrally flat and equivalent to the values at the boundaries. The Kurucz solar source function is used (Kurucz, 1992) to determine the solar input.

For liquid and ice spheres, the single-scattering albedo, asymmetry parameter, phase function moments, and extinction, absorption, and scattering efficiencies were calculated from Mie theory assuming spheres for both liquid and ice (Wiscombe, 1979, 1980). Mie calculations require the complex indices of refraction for liquid or ice as well as specification of the particle radius. Subsequently, the single-scattering properties were averaged for a lognormal distribution of particle sizes with geometric mean radius,

$r_{g}=\frac{r_{\mathrm{e}}}{\exp \left[2.5\left(\ln \sigma_{g}\right)^{2}\right]}$,

where $r_{\mathrm{e}}$ specifies effective radius; note that here $\sigma_{g}$ was chosen to be 0.331 . As described by Neshyba et al. (2003), $r_{\mathrm{e}}$ is defined as the area-weighted mean radius of the size distribution (Hansen and Travis, 1974) formulated for lognormal distributions by Reist (1993).

In addition to spheres, ice habits include rough and smooth plates and solid columns, and bullet rosettes. For these habits, single-scattering properties are from Yang et al. $(2005,2013)$, and no size averaging was done. Phase functions produced by these calculations were normalized using a Gaussian-fitted forward peak using an algorithm of McFarlane and Evans (2004). For more information about the spectral sensitivity in the infrared to different ice habits, refer to Yang et al. $(2005,2013)$.

In model layers containing the cloud, runDisort.m adds the wavenumber-dependent infrared cloud optical depth $(\tau)$ to the gaseous optical depth. The cloud optical depth is determined from the visible optical depth $\left(\tau_{\mathrm{vis}}\right)$ independently for each phase. For example, for liquid

$\tau_{\text {liq }}=\tau_{\text {vis,liq }} \frac{Q_{\text {ext,liq }}\left(r_{\text {liq }}\right)}{2}$,

where $Q_{\text {ext,liq }}$ is the extinction efficiency. (For ice, replace "liq" with "ice" in Eq. 2.) This work uses new temperaturedependent complex indices of refraction for liquid water at 240, 253, 263, 273, and $300 \mathrm{~K}$ (see Rowe et al., 2013, and references therein). To estimate the liquid optical depth of the cloud, optical depths are computed at two temperatures, one falling just below the mean cloud temperature and the other just above it, and then a weighted mean is taken. For ice, temperature dependencies are not included. Mixed-phase clouds are modeled as external mixture: the sum of liquid and ice optical depths is used.

\section{Specification of the atmospheric state}

The initial step in simulating infrared spectra is to specify the properties of the atmosphere. In the infrared, the relevant parameters are the vertical profiles of temperature and concentrations of gases that absorb and emit significantly in the spectral region of interest. First, a representative set of vertical profiles of temperature and concentration of atmospheric gases is selected (Sect. 3.1). Second, a realistic description of the macrophysical properties of clouds (i.e., height and physical thickness) is determined for each profile (Sect. 3.2). Finally, for each cloud, a range of microphysical properties (i.e., particle size, phase) and optical properties (i.e., optical depth) is defined (Sect. 3.3). Each spectrum represents a radiative transfer calculation of one of the profiles containing 
a cloud with a set of properties that satisfy the criteria of the study.

\subsection{Preparation of atmospheric profiles}

It is important that the profiles of temperature and humidity be realistic, and that the vertical position and extent of clouds also be realistic for individual profiles. Therefore, a small, representative sample of temperature and humidity profiles from radiosondes, which may include features such as cloud top inversions, was used instead of a climatological mean, which averages out such features. An initial set of 796 radiosondes launched in 2012 by the US Department of Energy (DOE) Atmospheric Radiation Measurement (ARM) program at the North Slope of Alaska (NSA) site (Stamnes et al., 1999) was examined. ARM NSA launched Vaisala RS-92 radiosondes, typically at 06:00 and 18:00 UTC, but sometimes at other times during the day. Possibly spurious temperature inversions within the lowest $100 \mathrm{~m}$ were removed by linearly interpolating to the surface. For reference, the radiosondes from Barrow in 2012 were similar to the radiosonde profiles from over the Arctic Ocean north of Barrow acquired during the Surface Heat Budget of the Arctic Ocean (SHEBA) (Uttal et al., 2002) drifting observatory in 1997 and 1998, but were slightly warmer and moister with slightly stronger temperature inversions. Radiosondes were only deemed valid for selection if they reached at least $10 \mathrm{~km}$, reducing the set from 796 to 784 . The profiles were linearly interpolated to a common grid of 41 vertical levels that are described in detail later in this section. References to the ARM-archived files containing the original radiosonde data are included with the data set.

The data set focuses on atmospheric profiles containing clouds. Because clear- and cloudy-sky profiles may differ, only profiles likely to represent cloudy times were selected. These were identified by the presence of one or more layers where the relative humidity with respect to water was greater than $95 \%$ between the surface and $8 \mathrm{~km}$, where Arctic clouds are typically found (Shupe et al., 2011). (Throughout this manuscript, "relative humidity" is defined as being with respect to water.) This threshold (rather than requiring $100 \%$ relative humidity) was chosen because humidity sensors are typically biased low in the dry polar atmosphere (Miloshevich et al., 2006; and Vömel et al., 2007; Rowe et al., 2008); relative humidities at model cloud heights were subsequently set to $100 \%$, as described below. Of the remaining 784 radiosondes, $522(67 \%)$ are good candidates for containing clouds. Since the number of calculations that can be performed is limited because of the long computational time, a random selection of 30 of the $522(6 \%)$ "cloudy" profiles is used for the final data set.

Figure 1 shows how the 30 selected profiles are distributed in time throughout the year. The selected profiles exclude some of the lowest surface temperatures because those conditions most likely represent clear skies. All seasons are rep-

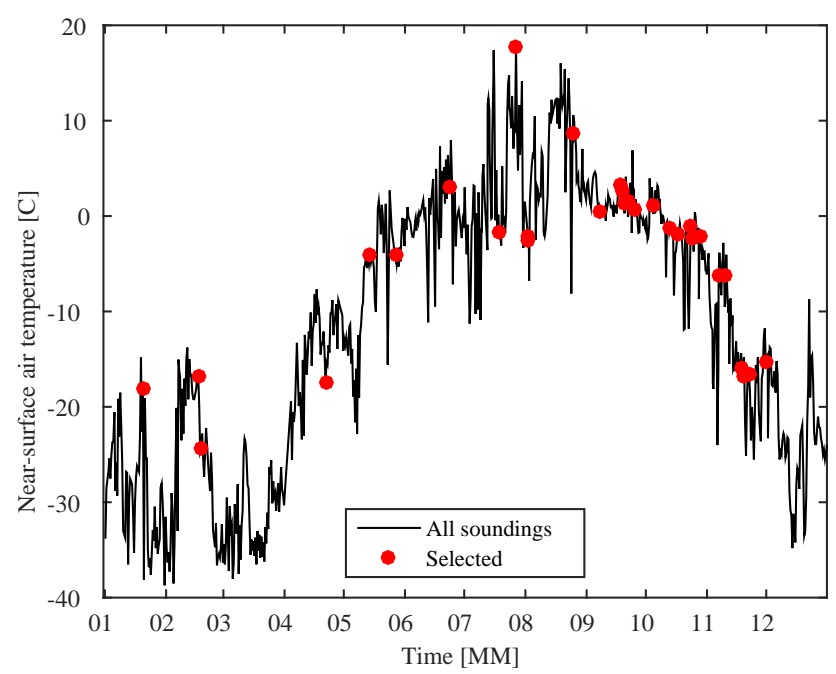

Figure 1. Temperature time series for the lowest level of each radiosonde from the 2012 Barrow data set. Red dots represent the 30 radiosondes that were selected for the data set.

resented, but more radiosondes are from summer and autumn than winter and spring, which is consistent with the fact that the cloud fraction is higher in summer and autumn (80-95\% of time) than in winter and spring (60-80\%) at Barrow (Shupe et al., 2011). The temperature and humidity profiles for these selections are similar in mean and variance to the full 2012 Barrow data set, as shown in Fig. 2a and b. The model atmosphere is divided into 40 layers extending from the surface to $60 \mathrm{~km}$ (atmospheric pressure at $60 \mathrm{~km}$ is less than $1 \mathrm{mb}$ ). Since levels in the stratosphere are relatively coarse, levels between 28 and $33 \mathrm{~km}$ are qualitatively set to fully capture the profile of ozone. Temperature, humidity, and trace gas concentrations are specified at 41 layer boundaries, spaced by $0.1 \mathrm{~km}$ from 0 to $1 \mathrm{~km}$, by $0.2 \mathrm{~km}$ from 1 to $2 \mathrm{~km}$, and then at 2.4, 2.8, 3.2, 4, 5, 6, 7, 8, 9, 10, 11, 12, $14,17,20,25,28,33,36.4,39.6,43,46,50,56$, and $60 \mathrm{~km}$. DISORT models the change in temperature across a layer by assuming the Planck function changes linearly with optical depth; this approximation leads to a requirement that the temperature differential across a layer be $<10 \mathrm{~K}$ (Stamnes et al., 2000). Thus to avoid errors due to large temperature variations across the layers, the boundaries are chosen such that temperature variations are $<7 \mathrm{~K}$ below $3 \mathrm{~km}$, where most clouds are positioned (see Sect. 3.2 for a discussion of cloud height) and $<10 \mathrm{~K}$ for all layers, as shown in Fig. 3.

For computational efficiency, we truncate the model atmosphere at the height above which layer optical depths begin to fall below $10^{-5}$. For the atmospheric layering chosen, at highly transparent wavenumbers, the optical depth can fall below $10^{-5}$ in the upper troposphere, while at other wavenumbers, layer optical depths may be $>10^{-5}$ up to $60 \mathrm{~km}$. Thus, at each wavenumber, the profiles used in the DISORT calculation terminate at $60 \mathrm{~km}$ or the height at 

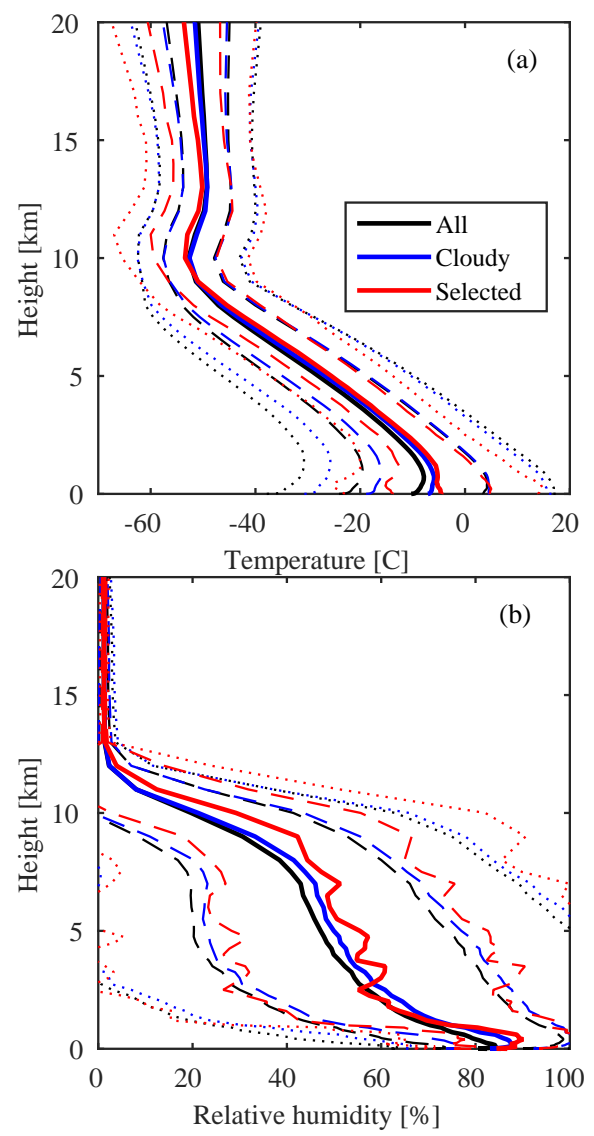

Figure 2. (a) Mean profile from 2012 radiosondes (black), mean "cloudy" profile (blue), and mean of selected radiosondes (red). (b) Same as (a), but for relative humidity. Dashed and dotted lines represent $\pm 1 \sigma$ and $2 \sigma$ variability, respectively.

which the layer optical depth falls to $10^{-5}$, whichever is lower. Radiance differences due to truncating the atmosphere when the optical depth falls below $10^{-5}$ are found to be quite small (sensitivity studies indicate that errors due to omitting these layers are on the order of $\left.10^{-4} \mathrm{~mW}\left(\mathrm{~m}^{2} \mathrm{sr} \mathrm{cm}^{-1}\right)^{-1}\right)$.

Humidity and temperature profiles above $18 \mathrm{~km}$ use the subarctic summer and subarctic winter standard atmospheres (McClatchey et al., 1972); all selected radiosoundings terminated above this height. Ozone, nitrous oxide, carbon monoxide, methane, and oxygen are also set using standard atmospheres (McClatchey et al., 1972). The subarctic winter model is used for the months of November through February, the subarctic summer is used for June through August, and the mean is used for the other months. Carbon dioxide concentrations are from monthly mean surface flask measurements from Barrow acquired in 2010 by the NOAA Earth System Research Laboratory (ESRL) Global Monitoring Division (GMD) (Conway et al., 2011); a constant mixing ratio with height is assumed.

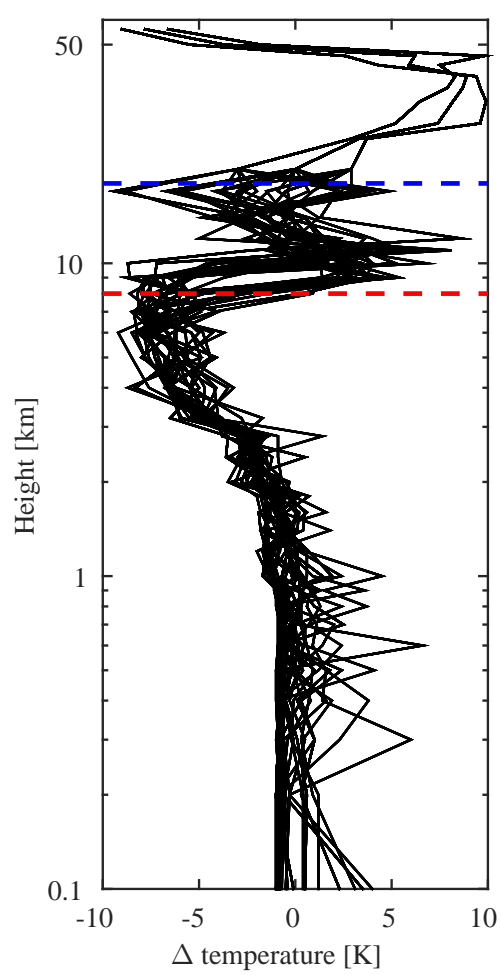

Figure 3. Temperature difference ( $T_{\text {layer top }}-T_{\text {layer bottom }}$ ) for each profile. The threshold for the temperature differential was $\pm 10 \mathrm{~K}$, which are the limits of the $x$ axis for the plot. The dashed red line is $8 \mathrm{~km}$, the highest level that clouds are positioned. The dashed blue line is $18 \mathrm{~km}$; above $18 \mathrm{~km}$ only standard atmospheres (subarctic winter, subarctic summer, and the transition seasons) are used. The lines are plotted using the center heights of the layers as the vertical coordinate.

\subsection{Cloud macrophysical properties}

Cloud macrophysical properties (cloud base and top heights) are set qualitatively by analysis of each of the 30 individual atmospheric profiles. Cloud base and top heights determine the physical thickness. The thermodynamic temperature structure of each cloud is that of the model layer(s) in which it was placed. As described in the previous section, at least one layer in each profile had a relative humidity greater than $95 \%$. This moist layer could sometimes span multiple model atmospheric layers, particularly in the lower atmosphere, where many model layers are physically thin, but where Arctic clouds are likely to be physically thick. When only a single layer boundary is moist, the adjacent layer (either above or below) with the highest humidity is identified as a cloud boundary. Some layers with relative humidity less than $95 \%$ that are adjacent to moist layer boundaries are identified as containing a cloud because other identifying characteristics were present, such as a cloud top inversion. In all "cloudy" layers, the relative humidity is set to $100 \%$. Seven of the 30 profiles can be considered cloudy at two nonsuccessive layers in the atmospheric column. These profiles 


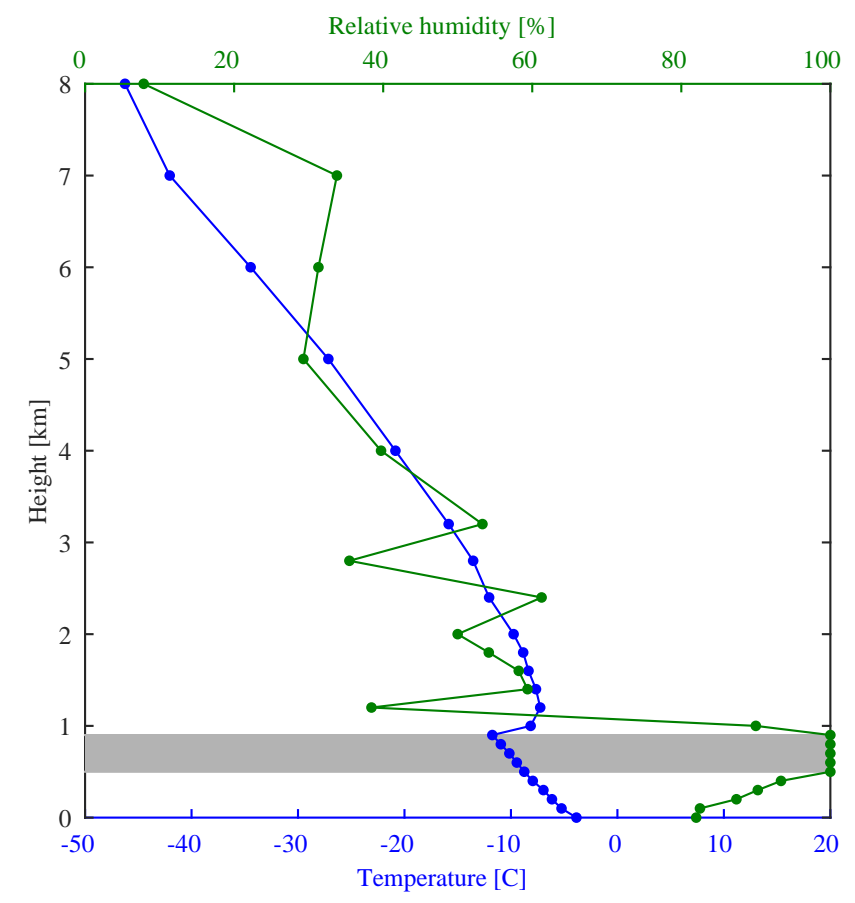

Figure 4. Example profile of temperature (blue) and relative humidity (green) from the surface to $8 \mathrm{~km}$. The cloud (gray shading) is placed between 0.5 and $0.9 \mathrm{~km}$, encompassing four model atmospheric layers. The temperature profile exhibits a cloud top inversion.

are used twice, once for the lower cloud and once for the upper cloud, but two clouds are never defined at the same time in keeping with the criteria of modeling single clouds only. Therefore, a total of 37 clouds were identified using the 30 profiles. Figure 4 shows an example of a profile; the cloud location is indicated in gray.

A summary of the cloud macrophysics is shown in Fig. 5. The distribution of cloud base heights (Fig. 5a) is similar to that reported for Barrow and SHEBA in Shupe et al. (2011), but the cloud top heights (Fig. 5a) and thus also the cloud thicknesses (Fig. 5b) are somewhat lower than those reported by Shupe et al. (2011). Distributions of cloud layer mean thermodynamic temperature (Fig. $5 \mathrm{c}$ ) are also reasonable when compared to the distributions reported for Barrow and SHEBA by Shupe et al. (2011). Figure 6 shows the relationship between cloud base height and other macrophysical properties. Mean cloud temperatures (Fig. 6a) generally decrease with increasing height, as is generally true in the atmosphere, with a weaker correlation in the lowest $1 \mathrm{~km}$, likely due to the near-surface temperature inversion, which is common in the Arctic. Because model layers were defined to get thicker going up in the atmosphere (the vertical layering was chosen for simplicity and consistency), there are no physically thin upper-level clouds (Fig. 6b), and thus the highest clouds have relatively large temperature gradients (Fig. 6c). To our knowledge, statistics of Arctic cloud physical thick-
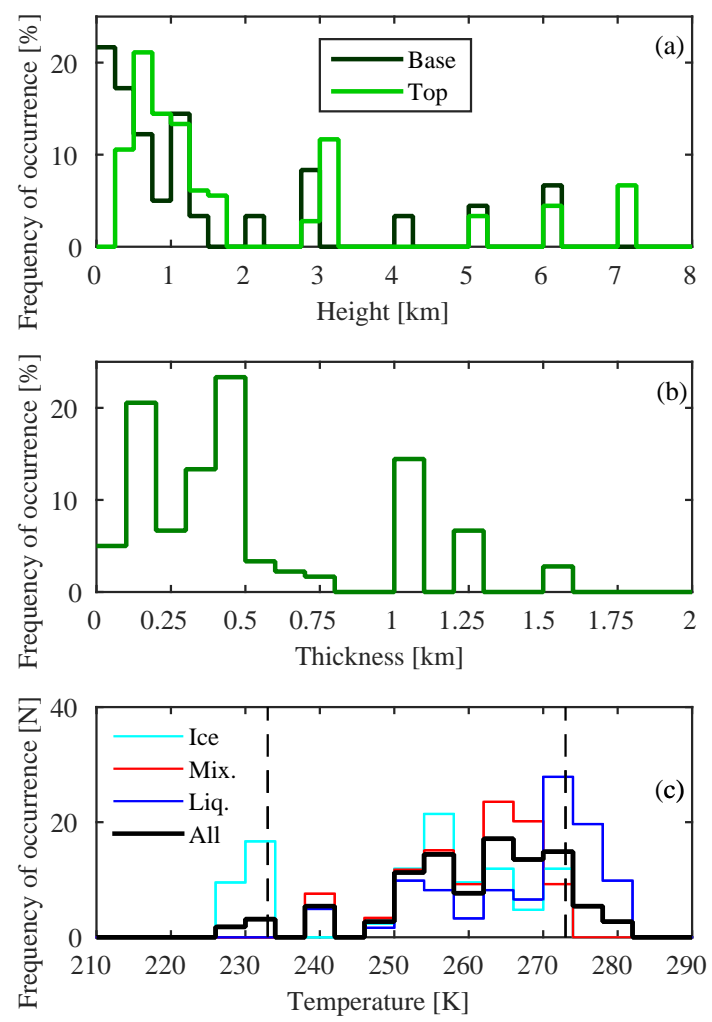

Figure 5. Distributions of macrophysical properties for the base set of 222 simulated clouds. (a) Cloud base height (black) and cloud top height (gray), (b) physical thickness, and (c) cloud mean temperature. The vertical lines in (c) represent the physical limits imposed on the minimum temperature that liquid may be included $(233 \mathrm{~K})$ and the maximum temperature that ice may be included $(273 \mathrm{~K})$. Between these thresholds examples of liquid-only, ice-only, and mixed-phase clouds are simulated.

ness as a function of height are not available in the literature, but ice clouds have been observed to be physically thick (e.g., Miller et al., 2015) and all clouds in the data set are within the range of thickness typically observed in the Arctic (Shupe et al., 2011).

The liquid and ice distribution is vertically homogeneous in the simulations making up the base data set. However, the distribution of ice and liquid in Arctic stratocumulus mixedphase clouds, which are frequently observed (e.g., Shupe, 2011), is not vertically homogeneous. Rather, in these clouds the liquid is predominantly confined to a physically thin layer at the top of the cloud (e.g., Shupe, 2011). Thus mixed-phase cloud simulations are also provided with liquid in the top model layer and ice in the layers below; these simulations are otherwise identical to simulations in the base data set, allowing testing of the effect of liquid and ice distribution on retrievals. Similarly, cloud optical depth varies in clouds; thus simulations are also included in which the optical depth is thicker at the cloud center and thinner at the boundaries (again, the simulations are otherwise identical to cases in the 

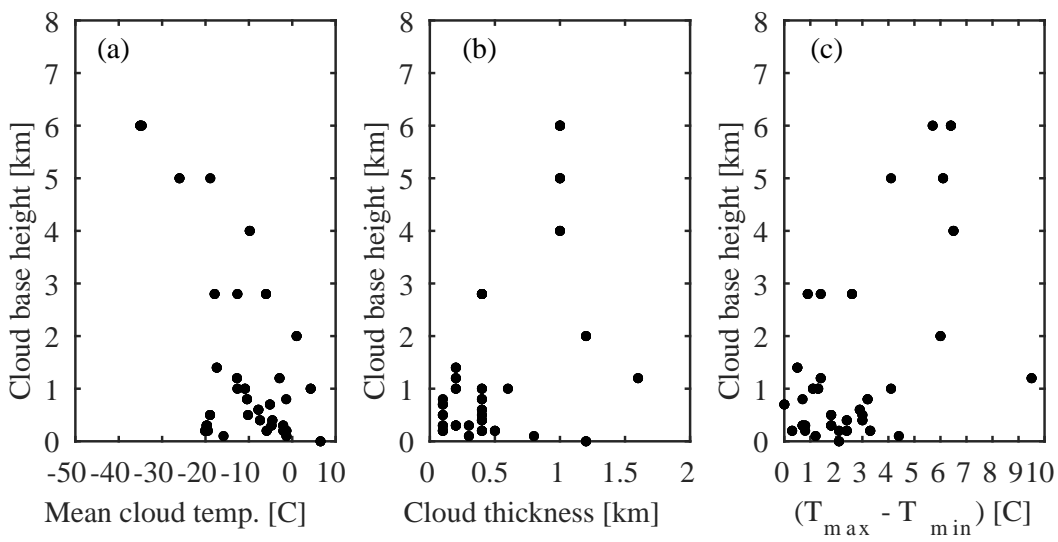

Figure 6. Relationships between the macrophysical properties for the 37 cloud macrophysical scenarios. (a) Cloud base height versus cloud layer mean temperature, (b) cloud base height versus cloud physical thickness, and (c) cloud base height versus cloud layer temperature differential.

base data set). Liquid and ice partitioning and cloud vertical homogeneity in Arctic clouds are not yet fully understood; other configurations can be made available on request.

\subsection{Cloud microphysical and optical properties}

This section describes the parameterization of cloud microphysical and optical properties, including optical depth, particle size (effective radius), thermodynamic phase (ice fraction), ice water path (IWP), and liquid water path (LWP). For each simulation, visible optical depth, ice fraction, effective radius of liquid (if present), and effective radius of ice (if present) are randomly selected from pre-determined distributions for the simulations; IWP and LWP are calculated based on these selections.

Figure 7 shows the distributions of each of the parameterized microphysical and optical properties for the base data set of 222 simulations. The distributions of effective radii are modeled as gamma distributions to be similar to distributions retrieved from ground-based infrared spectral observations at SHEBA (Turner, 2005) and Eureka, Canada $\left(80.053^{\circ} \mathrm{N}\right.$, $86.417^{\circ} \mathrm{W} ; 10 \mathrm{~m}$ ) (Cox et al., 2014). The means were set to $10 \mu \mathrm{m}$ for liquid and $25 \mu \mathrm{m}$ for ice, which are reasonable estimates for Arctic particle sizes (Turner, 2005). Following the results from Cox et al. (2014) and Turner (2005), the distribution shape parameter is set subjectively to $\alpha=5$ for liquid and $\alpha=0$ for ice. An additional consideration in setting the shape parameter is to ensure that the distributions overlap, as they do in the real atmosphere, to make sure that retrieval algorithms tested using this data set do not rely on particle size to determine phase. The overlap is approximately one-third of the area under each distribution.

Cloud visible optical depths are selected randomly from a uniform distribution of transmission $(\Im)$ between 0 and 0.98 ; the visible optical depth is then $-\ln [\Im]$. The maximum transmission is set to 0.98 because this is approximately equiva-
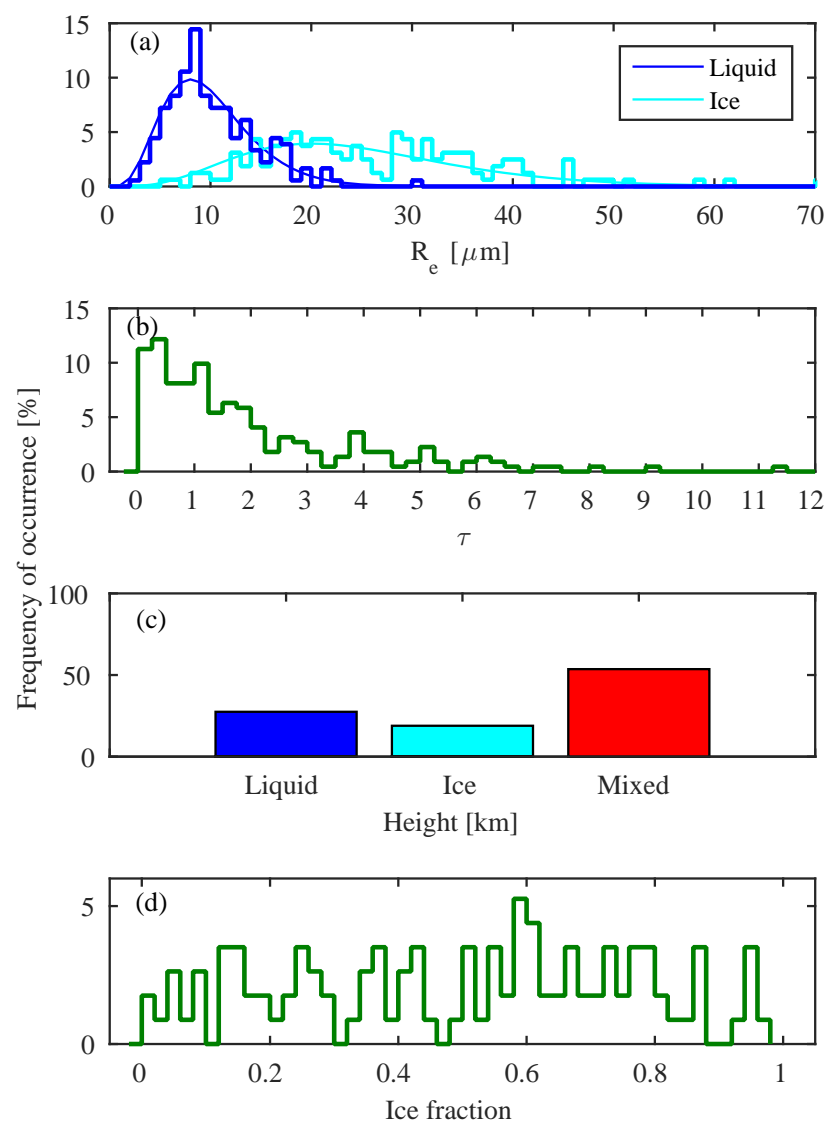

Figure 7. Distributions of microphysical properties for the 222 simulated clouds. (a) Effective radius, (b) total (ice + liquid) optical depth, (c) phase, and (d) ice fraction (fraction of total optical depth) for mixed-phase clouds. 

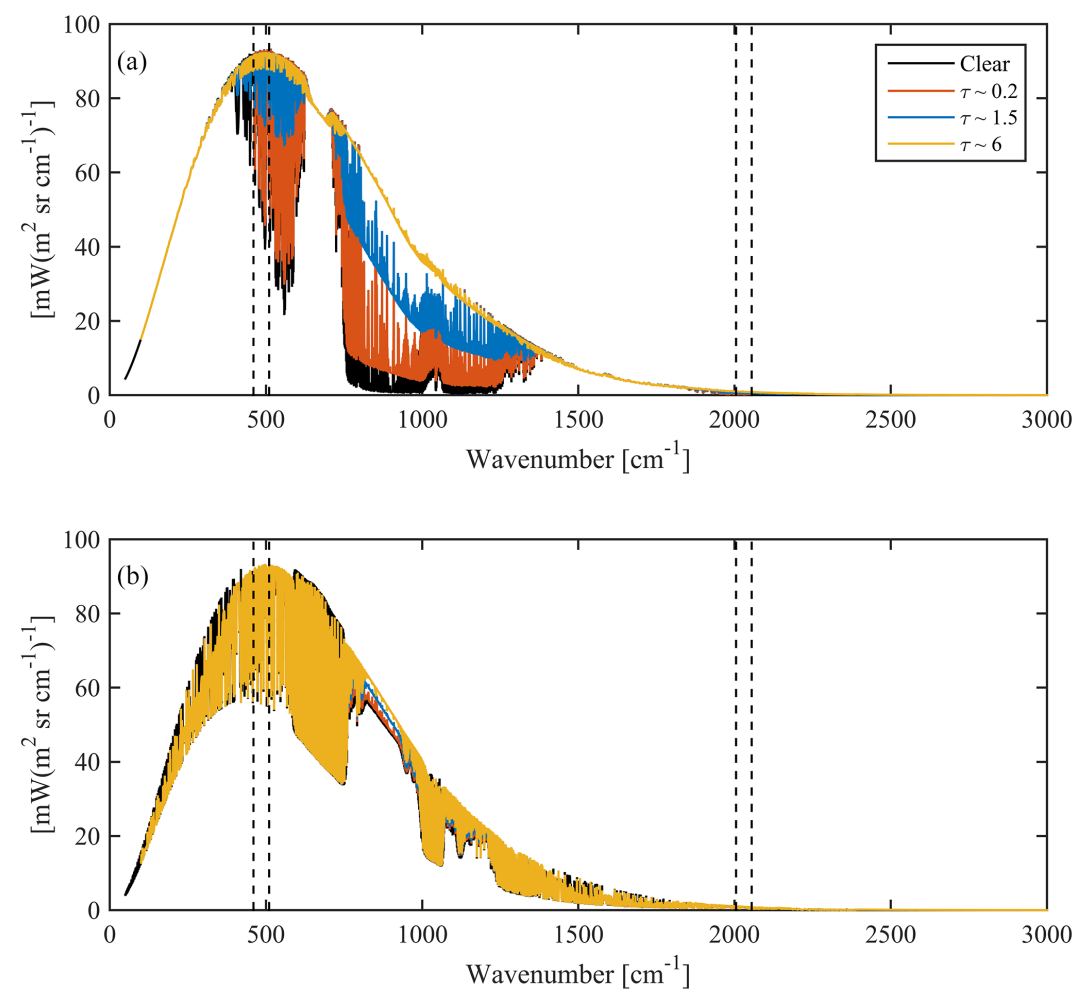

Figure 8. Example simulated radiances for (a) downwelling from the perspective of the surface and (b) same case as (a), but for upwelling radiances from the perspective of the top of the atmosphere. Channel edges and channel overlap between channel 1 and channel 2 are marked by vertical dashed lines near $500 \mathrm{~cm}^{-1}$ and similarly near $2000 \mathrm{~cm}^{-1}$ for channel 2 and channel 3 . Each panel shows line-by-line clear-sky radiances (black) and $0.01 \mathrm{~cm}^{-1}$ resolution spectra for three example clouds with optical depths of approximately 0.2 (red), 1.5 (blue), and 6 (yellow).

lent to an optical depth of 0.02 ; such a small optical depth is typically below the threshold for detecting a cloud for most currently used instruments and was chosen purposefully so the data set is useful for testing the limits of retrieval capability. Similarly, the upper optical depth threshold is above the typical threshold for sensitivity to cloud microphysical properties in the infrared (optical depth of $\sim 6$ ), allowing for testing retrieval limitations. The resulting distribution, shown in Fig. 7b, is quasi-logarithmic, as are distributions of optical depth retrieved from infrared observations in the Arctic (Turner, 2005; Cox et al., 2014). This method for building an optical depth distribution is practical because it results in many thin clouds, but not as many as an exponential distribution, and only a few clouds with optical depths greater than 6-7, above which clouds are nearly optically opaque.

Phase partitioning is set so that the probability of liquidonly and ice-only clouds is each $1: 6$, and the probability of a mixed-phase cloud is $2: 3$. The actual proportions of the final data set are shown in Fig. 7c. These proportions are not meant to reflect a climatological distribution representative of the Arctic but rather to ensure that a sufficient number of each phase is represented especially for mixed-phase clouds, which are common in the Arctic (Turner, 2005; Shupe et al.,
2008; de Boer et al., 2009; Shupe, 2011; Cox et al., 2014). Ice fractions for mixed-phase clouds are drawn from a uniform distribution between 0.01 and 0.99 . The distribution of ice fraction in mixed-phase clouds in the final data set is shown in Fig. 7d.

In addition to the base data set, four cases of liquid-topped clouds are also provided, along with four cases of clouds with optical depths that are thinner at the cloud top and bottom. Also, a subset of five cases representing low, middle, and high clouds (including mixed-phase and ice-only examples) is provided with simulations that make use of a variety of ice crystal habits using the single-scattering databases described by Yang et al. $(2005,2013)$. The ice habits are as follows: rough and smooth columns, rough and smooth plates, and bullet rosettes. These shapes have been observed in Arctic clouds (e.g., Korolev and Isaac, 1999; Lawson et al., 2001; Verlinde et al., 2007; McFarquhar et al., 2007). Each case was recalculated holding all other cloud and atmospheric properties from the base data set constant. In addition to these 38 simulations, additional simulations with different configurations can be made available on request. 

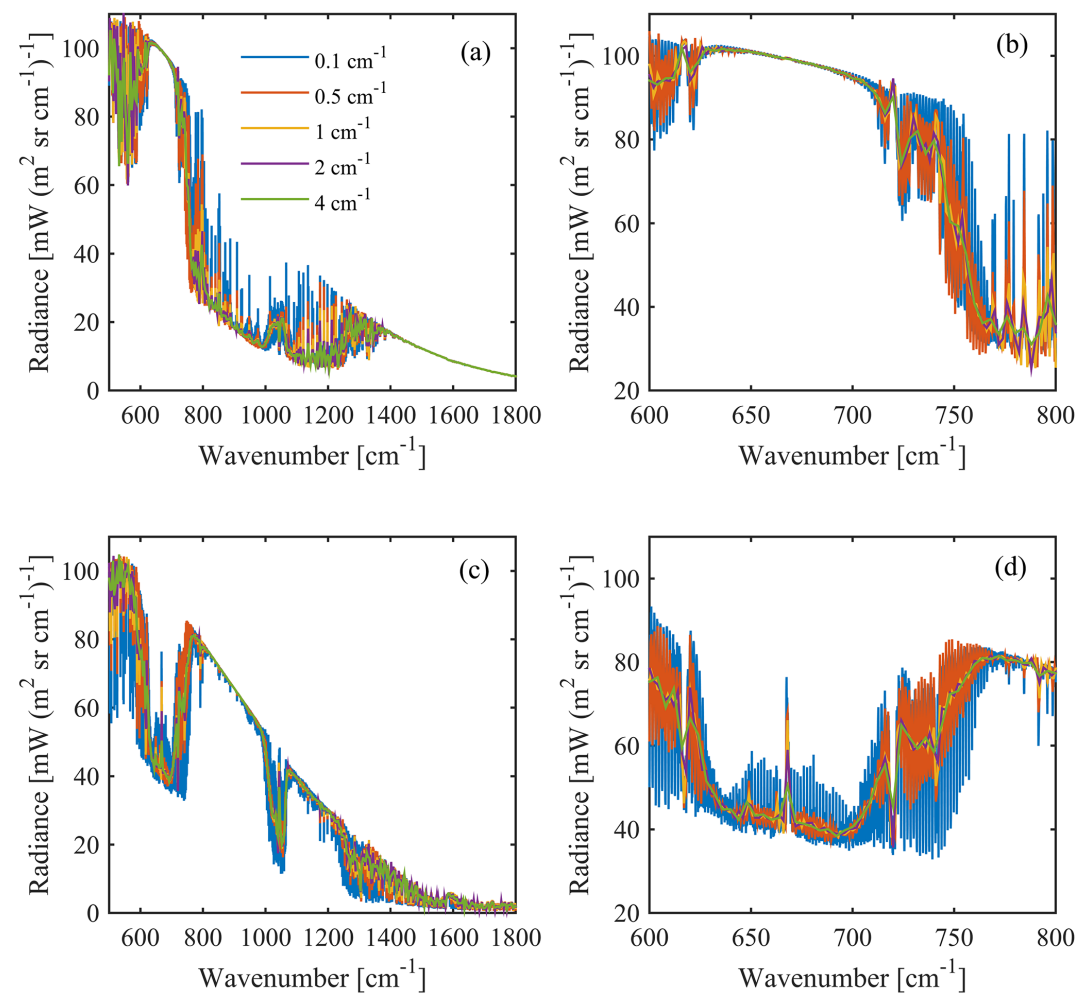

Figure 9. Simulated downwelling radiances from 500 to $1800 \mathrm{~cm}^{-1}$ for an example case $(\tau=0.65)$ from the perspective of the surface $(\mathbf{a}$, b) and simulated upwelling radiances from same case from the perspective of the top of the atmosphere (c, d). The top row (a, c) and the bottom row $(\mathbf{c}, \mathbf{d})$ each show the same data, but with the $x$ axis narrowed to $600-800 \mathrm{~cm}^{-1}$ to illustrate the wing of the $15 \mu \mathrm{m} \mathrm{CO}_{2}$ band, where there is considerable spectral structure. In each panel the $0.01 \mathrm{~cm}^{-1}$ spectral resolution base data are convolved to $0.1 \mathrm{~cm}^{-1}$ (blue), $0.5 \mathrm{~cm}^{-1}$ (red), $1 \mathrm{~cm}^{-1}$ (yellow), $2 \mathrm{~cm}^{-1}$ (purple), and $4 \mathrm{~cm}^{-1}$ (green).

\section{Modeled infrared spectra}

Figure $8 \mathrm{a}$ and $\mathrm{b}$ show examples of simulated line-byline spectra (the spectral grid is $\sim 2.55 \times 10^{-4} \mathrm{~cm}^{-1}$ for LBLRTM and $\sim 0.01 \mathrm{~cm}^{-1}$ for DISORT) in three spectral ranges (or channels). For each atmospheric profile, clear-sky radiances were created using LBLRTM and are provided together with the cloudy-sky profiles (upwelling clear-sky radiances created with LBLRTM use the same surface emissivity/reflectivity characteristics as cloudy-sky radiances created with DISORT). An overlap of $50 \mathrm{~cm}^{-1}$ at the edges of the channels ensures that errors incurred near the edges are negligible when combining the channels. The clear-sky radiance is also shown for reference. The effect of the cloud is to increase the baseline of the spectrum, which is close to zero in the atmospheric window (800 to $1300 \mathrm{~cm}^{-1}$ ), for the clear-sky case. For the cloud shown, the cloud is thin enough that strong gaseous emission lines are clearly evident.

The simulations can be convolved with an instrument response function to produce a simulation that matches the output from an actual instrument (e.g., Beer, 1992). For example, Fig. 9a and $\mathrm{b}$ show a downwelling spectrum from the perspective of the surface at a variety of different resolutions $\left(0.1,0.5,1,2\right.$, and $\left.4 \mathrm{~cm}^{-1}\right)$, where the spectra were created by convolving the line-by-line spectra with the sinc function (or, in practice, by multiplying the corresponding interferograms by boxcar functions and taking the Fourier transform). Figure $9 \mathrm{c}$ and $\mathrm{d}$ show the same for upward directed radiances from the perspective of the top of the atmosphere (TOA, defined here as $60 \mathrm{~km}$ ), representing radiances that would be measured from satellites.

Spectra at a variety of instrument resolutions can be used to test cloud height retrievals and microphysical property retrievals, as well as to test methods for running DISORT using gaseous optical depths that have been modified to account for instrument resolution. For uses such as these, the sources of retrieval errors can be tested as follows. Random noise can be simulated and added to the simulated radiances. To simulate errors in the atmospheric state, retrievals can be performed using atmospheric profiles that have been perturbed. Because the data set consists of so many cases, errors can be drawn from a random distribution characterized by the desired mean and standard deviation so that errors vary from case to case. Because the data are simulated, these sources of error, as well as model errors, can be quantified. 


\section{Conclusions}

A synthetic, monochromatic (line-by-line) resolution data set of spectral infrared radiances is described that is based on the atmospheric state and cloud conditions typical of the western Arctic. The data set includes radiative transfer calculations from the perspective of the surface and the top of the atmosphere $(60 \mathrm{~km})$ and is thus applicable to researchers working with surface- or satellite-based measurements. The data set is designed to provide an idealized framework for the development and testing of cloud-property retrieval algorithms in which the assumptions are controlled and the properties of the clouds are known a priori. This addresses an important knowledge gap demonstrated by the results of numerous studies reporting systematic but only weakly traceable differences in intercomparisons between measurement and retrieval methodologies (e.g., Shupe et al., 2008; Dong et al., 2008; Liu et al., 2010; Minnis et al., 2011; Vogelmann et al., 2012; Zhao et al., 2012; Chan and Comiso, 2013). The data set may also be useful for other applications as well, such as research on cloud-surface radiative interactions, trace gas retrievals, or investigations of the effect of instrument resolution. The framework for creating additional simulations is in place, which enables simulation design to be tailored to the unique needs of individual studies. Interested researchers requiring different configurations are encouraged to contact the authors for assistance.

\section{Data availability}

Upwelling (at $60 \mathrm{~km}$ ) and downwelling (at the surface) simulated clear-sky and all-sky infrared spectra, cloud properties, and atmospheric state profiles of temperature, pressure, and radiatively active gases are available in the Network Common Data Format (netCDF) (e.g., http://www.unidata.ucar. edu/software/netcdf/). The data set contains 260 unique cases from 50 to $3000 \mathrm{~cm}^{-1}$ (3.3 to $200 \mu \mathrm{m}$ ) at a spectral resolution of $\sim 0.01 \mathrm{~cm}^{-1}$ (all sky) and line-by-line resolution (clear sky). The spectral range is distributed across three channels (100-510, 460-2055, and 2005-3000 $\mathrm{cm}^{-1}$ ), each in separate files. Interested researchers may download the data from NSF Arctic Data Center (http://www.arcticdata.io) and are encouraged to cite the use of the data using the associated digital object identifier (doi:10.5065/D61J97TT).

Author contributions. C. J. Cox, V. P. Walden, and P. M. Rowe conceived and designed the data set and performed the simulations. P. M. Rowe and S. P. Neshyba developed computer code used for the simulations. C. J. Cox prepared the manuscript with contributions from all co-authors.

Acknowledgements. This work was supported by the $\mathrm{Na}-$ tional Science Foundation's Arctic Observing Network (AON)
(NSF ARC-1108451). C. J. Cox also received support from the NOAA Climate Program Office (CPO) Arctic Research Program (ARP) and the Cooperative Institute for Research in Environmental Sciences (CIRES) Visiting Fellows Program. P. M. Rowe received support from NSF award ARC-1108451 and from Consejo Nacional de Ciencia y Tecnologia CONICYTAnillos, Preis ACT 1410. S. P. Neshyba was supported by NSF award CHE-1306366 for this work. The NOAA Earth System Research Laboratory (ESRL) Global Monitoring Division (GMD) archive of $\mathrm{CO}_{2}$ measurements is available from $\mathrm{ftp} / / /$ aftp.cmdl.noaa.gov/data/trace_gases/co2/flask/surface/.

The US Dept. of Energy (DOE) Atmospheric Radiation Measurement (ARM) program data are available from the ARM archive, http://www.arm.gov. Moderate Resolution Imaging Spectrometer (MODIS) University of California, Santa Barbara (UCSB), emissivity library is available from http://www.icess.ucsb.edu/modis/EMIS/html/em.html. We acknowledge the NSF Arctic Data Center data portal, where the data are archived for community use: http://www.arcticdata.io.

Edited by: A. Kokhanovsky

\section{References}

Alvarado, M. J., Payne, V. H., Mlawer, E. J., Uymin, G., Shephard, M. W., Cady-Pereira, K. E., Delamere, J. S., and Moncet, J.L.: Performance of the Line-By-Line Radiative Transfer Model (LBLRTM) for temperature, water vapor, and trace gas retrievals: recent updates evaluated with IASI case studies, Atmos. Chem. Phys., 13, 6687-6711, doi:10.5194/acp-13-6687-2013, 2013.

Baum, B. A., Kratz, D. P., Yang, P., Ou, S. C., Hu, Y., Soulen, P. F., and Tsay, S.-C. L.: Remote sensing of cloud properties using MODIS airborne simulator imagery during SUCCESS 1. Data and models, J. Geophys. Res., 105, 11767-11780, doi:10.1029/1999JD901089, 2000.

Beer, R.: Remote sensing by Fourier transform spectrometry, WileyInterscience, New York, 1992.

Bugliaro, L., Zinner, T., Keil, C., Mayer, B., Hollmann, R., Reuter, M., and Thomas, W.: Validation of cloud property retrievals with simulated satellite radiances: a case study for SEVIRI, Atmos. Chem. Phys., 11, 5603-5624, doi:10.5194/acp-11-5603-2011, 2011.

Chan, M. A. and Comiso, J. C.: Arctic cloud characteristics as derived from MODIS, CALIPSO, and CloudSat, J. Climate, 26, 3285-3306, doi:10.1175/JCLI-D-12-00204.1, 2013.

Clough, S. A., Iacono, J. M., and Moncet, J.-L.: Line-by-line calculations of atmospheric fluxes and cooling rates: Application to water vapor, J. Geophys. Res.-Atmos., 97, 15761-15785, doi:10.1029/92JD01419, 1992.

Clough, S. A., Shephard, M. W., Mlawer, E. J., Delamere, J. S., Iacono, M. J., Cady-Pereira, K., Boukabara, S., and Brown, P. D.: Atmospheric radiative transfer modeling: a summary of the AER codes, Short Communication, J. Quant. Spectrosc. Ra., 91, 233-244, doi:10.1016/j.jqsrt.2004.05.058, 2005.

Conway, T. J., Lang, P. M., and Masarie, K. A.: Atmospheric carbon dioxide dry air mole fractions from the NOAA ESRL Carbon Cycle Cooperative Global Air Sampling Network, 1968-2010, available at: ftp://aftp.cmdl.noaa.gov/data/trace_gases/co2/flask/ surface/ (last access: 1 November 2012), 2011. 
Cox, C. J., Walden, V. P., and Rowe, P. M.: A comparison of atmospheric conditions at Eureka, Canada, and Barrow, Alaska (2006-2008), J. Geophys. Res.-Atmos., 117, D12204, doi:10.1029/2011JD017164, 2012.

Cox, C. J., Turner, D. D., Rowe, P. M., Shupe, M. D., and Walden, V. P.: Cloud microphysical properties retrieved from downwelling infrared radiance measurements made at Eureka, Nunavut, Canada (2006-09), J. Appl. Meteorol. Clim., 53, 772791, doi:10.1175/JAMC-D-13-0113.1, 2014.

de Boer, G., Eloranta, E. W., and Shupe, M. D.: Arctic mixed-phase stratiform cloud properties from multiple years of surface-based measurements at two high-latitude locations, J. Atmos. Sci., 66, 2874-2887, doi:10.1175/2009JAS3029.1, 2009.

Delamere, J. S., Clough, S. A., Payne, V. H., Mlawer, E. J., Turner, D. D., and Gamache, R. R.: A far-infrared radiative closure study in the Arctic: Application to water vapor, J. Geophys. Res.Atmos., 115, D17106, doi:10.1029/2009JD012968, 2010.

Dong, X. and Mace, G. G.: Arctic stratus cloud properties and radiative forcing derived from ground-based data collected at Barrow, Alaska, J. Climate, 16, 445-461, doi:10.1175.15200442(2003)016<0445:ASCPAR>2.0.CO;2, 2003.

Dong, X., Minnis, P., Xi, B., Sun-Mack, S., and Chen, Y.: Comparison of CERES-MODIS stratus cloud properties with ground-based measurements at the DOE ARM Southern Great Plains site, J. Geophys. Res.-Atmos., 113, D03204, doi:10.1029/2007JD008438, 2008.

Dong, X., Xi, B., Crosby, K., Long, C. N., Stone, R. S., and Shupe, M. D.: A 10 year climatology of Arctic cloud fraction and radiative forcing at Barrow, Alaska, J. Geophys. Res.-Atmos., 115, D17212, doi:10.1029/2009JD013489, 2010.

Garrett, T. J. and Zhao, C.: Increased Arctic cloud longwave emissivity associated with pollution from mid-latitudes, Nature, 440, 787-789, doi:10.1038/nature04636, 2006.

Garrett, T. J. and Zhao, C.: Ground-based remote sensing of thin clouds in the Arctic, Atmos. Meas. Tech., 6, 1227-1243, doi:10.5194/amt-6-1227-2013, 2013.

Hansen, J. E. and Travis, L. D.: Light scattering in planetary atmospheres, Space Sci. Rev., 16, 527-610, doi:10.1007/BF00168069, 1974.

Jin, H. and Nasiri, S. L.: Evaluation of AIRS cloud-thermodynamicphase determination with CALIPSO, J. Appl. Meteor. Climatol., 53, 1012-1027, doi:10.1175/JAMC-D-13-0137.1, 2014.

Kahn, B. H., Irion, F. W., Dang, V. T., Manning, E. M., Nasiri, S. L., Naud, C. M., Blaisdell, J. M., Schreier, M. M., Yue, Q., Bowman, K. W., Fetzer, E. J., Hulley, G. C., Liou, K. N., Lubin, D., Ou, S. C., Susskind, J., Takano, Y., Tian, B., and Worden, J. R.: The Atmospheric Infrared Sounder version 6 cloud products, Atmos. Chem. Phys., 14, 399-426, doi:10.5194/acp-14-399-2014, 2014.

Karlsson, K.-G. and Dybbroe, A.: Evaluation of Arctic cloud products from the EUMETSAT Climate Monitoring Satellite Application Facility based on CALIPSO-CALIOP observations, Atmos. Chem. Phys., 10, 1789-1807, doi:10.5194/acp-10-17892010, 2010.

Kay, J. E. and Gettelman, A.: Cloud influence on and response to seasonal Arctic sea ice loss, J. Geophys. Res.-Atmos., 114, D18204, doi:10.1029/2009JD011773, 2009.

Korolev, A. V. and Isaac, G. A.: Ice particle habits in Arctic clouds, Geophys. Res. Lett., 26, 1299-1302, doi:10.1029/1999GL900232, 1999.
Kurucz, R. L.: Synthetic infrared spectra, in: Infrared Solar Physics, IAU Symp. 154, edited by: Rabin, D. M. and Jefferies, J. T., Kluwer, Acad., Norwell, MA, 1992.

Lawson, R. P., Baker, B. A., Schmitt, C. G., and Jensen, T. L.: An overview of microphysical properties of Arctic clouds observed in May and July 1998 during FIRE ACE, J. Geophys. Res.Atmos., 106, 14989-15014, doi:10.1029/2000JD900789, 2001.

Li, J., Huang, H.-L., Liu, C.-Y., Yang, P., Schmit, T. J., Wei, H., Weisz, E., Guan, L., and Menzel, W. P.: Retrieval of cloud microphysical properties from MODIS and AIRS, J. Appl. Meteorol., 44, 1526-1543, doi:10.1175/JAM2281.1, 2005.

Liu, Y., Ackerman, S. A., Maddux, B. C., Key, J. R., and Frey, R. A.: Errors in cloud detection over the Arctic using a satellite imager and implications for observing feedback mechanisms, J. Climate, 23, 1894-1907, doi:10.1175/2009JCLI3386.1, 2010.

McClatchey, R. A., Fenn, R. W., Selby, J. E. A., Volz, F. E., and Garing, J. S.: Optical properties of the atmosphere, 3rd Edn., Tech. Rep. AFCRL-72-0497, 108 pp., Air Force Geophys. Lab., Hanscom AFB, Mass., 1972.

McFarlane, S. A. and Evans, K. F.: Clouds and shortwave fluxes at Nauru. Part II: Shortwave flux closure, J. Atmos. Sci., 61, 26022615, doi:10.1175/JAS3299.1, 2004.

McFarquhar, G. M., Zhang, G., Poellot, M. R., Kok, G. L., McCoy, R., Tooman, T., Fridlind, A., and Heymsfield, A. J.: Ice properties of single-layer stratocumulus during the Mixed-Phase Arctic Cloud Experiment: 1. Observations, J. Geophys. Res.-Atmos., 112, D24201, doi:10.1029/2007JD008633, 2007.

Miller, N. B., Shupe, M. D., Cox, C. J., Walden, V. P., Turner, D. D., and Steffen, K.: Cloud Radiatve Forcing at Summit, Greenland, J. Climate, 28, 6267-6280, doi:10.1175/JCLI-D-150076.1, 2015.

Miloshevich, L. M., Vömel, H., Whiteman, D. N., Lesht, B. M., Schmidlin, F. J., and Russo, F.: Absolute accuracy of water vapor measurements from six operational radiosonde types launched during AWEX-G and implications for AIRS validation, J. Geophys. Res.-Atmos., 111, D09S10, doi:10.1029/2005JD006083, 2006.

Minnis, P., Sun-Mack, S., Chen, Y., Khaiyer, M. M., Yuhong, Y., Ayers, K., Brown, R. R., Dong, X., Gibson, S. C., Heck, P. W., Lin, B., Nordeen, M. L., Nguyen, L., Palikonda, R., Smith Jr., W. L., Spangenberg, S. A., Trepte, Q. Z., and Xi, B.: CERES Edition-2 cloud property retrievals using TRMM VIRS and Terra and Aqua MODIS data - Part II: Examples of average results and comparisons of with other data, IEEE T. Geosci. Remote, 49, 4401-4430, doi:10.1109/TGRS.2011.2144602, 2011.

Neshyba, S. P., Grenfell, T. C., and Warren, S. G.: Representation of a non-spherical ice particle by a collection of independent spheres for scattering and absorption of radiation: 2 . Hexagonal columns and plates, J. Geophys. Res., 108, 4448, doi:10.1029/2002JD003302, 2003.

Pincus, R., Platnick, S., Ackerman, S. A., Hemler, R. S., and Hoffman, R. J. P.: Reconciling simulated and observed views of clouds: MODIS, ISCCP, and the limits of instrument simulators, J. Climate, 25, 4699-4720, doi:10.1175/JCLI-D-1100267.1, 2012.

Rathke, C., Fischer, J., Neshyba, S., and Shupe, M.: Improving IR cloud phase determination with 20 microns spectral observations, Geophys. Res. Lett., 29, 50-1-50-4, doi:10.1029/2001GL014594, 2002a. 
Rathke, C., Neshyba, S., Shupe, M., Rowe, P., and Rivers, A.: Radiative and microphysical properties of Arctic stratus clouds from multiangle downwelling infrared radiances, J. Geophys. Res., 107, AAC 12-1-AAC 12-13. doi:10.1029/2001JD001545, 2002 b.

Reist, P. C.: Aerosol Science and Technology, McGraw-Hill, New York, 1993.

Rothman, L. S., Gordon, I. E., Barbe, A., Benner, D. C., Bernath, P. F., Birk, M., Boudon, V., Brown, L. R., Campargue, A., Champiom, J.-P., Chance, K., Coudert, L. H., Dana, V., Devi, V. M., Fally, S., Flaud, J.-M., Gamache, R. R., Goldman, A., Jacquemart, D., Kleiner, I., Lacome, N., Lafferty, W. J., Mandin, J.-Y., Massie, S. T., Mikhailenko, S. N., Miller, C. E., Moazzen-Ahmadi, N., Maumenko, O. V., Nikitin, A. V., Orphal, J., Perevalov, V. I., Perrin, A., Predoi-Cross, A., Rinsland, C. P., Rotger, M., Šimečková, M., Smith, M. A. H., Sung, K., Tashkun, S. A., Tennyson, J., Toth, R. A., Vandaele, A. C., and Vander Auwera, J.: The HITRAN 2008 molecular spectroscopic database, J. Quant. Spectrosc. Ra., 110, 533-572, doi:10.1016/j.jqsrt.2009.02.013, 2009.

Rowe, P. M., Miloshevich, L. M., Turner, D. S., and Walden, V.: Dry Bias in Vaisala RS90 radiosonde humidity profiles over Antarctica, J. Atmos. Ocean. Tech., 25, 1529-1541, doi:10.1175/2008JTECHA1009.1, 2008.

Rowe, P. M., Neshyba, S., and Walden, V. P.: Radiative consequences of low-temperature infrared refractive indices for supercooled water clouds, Atmos. Chem. Phys., 13, 11925-11933, doi:10.5194/acp-13-11925-2013, 2013.

Shupe, M.: Clouds at Arctic atmospheric observatories: Part II. Thermodynamic phase characteristics, J. Appl. Meteorol. Clim., 50, 645-661, doi:10.1175/2010JAMC2468.1, 2011.

Shupe, M. D., Daniel, J. S., de Boer, G., Eloranta, E. W., Kollias, P., Luke, E., Long, C. N., Turner, D. D., and Verlinde, J.: A focus on mixed-phase clouds: The status of ground-based observational methods, B. Am. Meteorol. Soc., 87, 1549-1562, doi:10.1175/2008BAMS2378.1, 2008.

Shupe, M. D., Walden, V. P., Eloranta, E., Uttal, T., Campbell, J. R., Starkweather, S. M., and Shiobara, M.: Clouds at Arctic atmospheric observatories. Part I. Occurrence and macrophysical properties, J. Appl. Meteorol. Clim., 50, 626-644, doi:10.1175/2010JAMC2567.1, 2011.

Stamnes, K., Tsay, S.-C., Wiscombe, W. J., and Jayaweera, K.: Numerically stable algorithm for discrete-ordinate-method radiative transfer in multiple scattering and emitting layered media, Appl. Optics, 27, 2502-2509, doi:10.1364/AO.27.002502, 1988.

Stamnes, K., Ellingson, R. G., Curry, J. A., Walsh, J. E., and Zak, B. D.: Review of science issues, deployment strategy, and status for the ARM North Slope of Alaska - Adjacent Arctic Ocean climate research site, J. Climate, 12, 46-63, doi:10.1175/15200442-12.1.46, 1999.

Stamnes, K., Tsay, S.-C., Wiscombe, W., and Laszlo, I.: DISORT, a general-purpose Fortran program for discrete-ordinate-method radiative transfer in scattering and emitting layered media: Documentation of methodology, Tech. rep., Dept. of Physics and Engineering Physics, Stevens Institute of Technology, Hoboken, NJ 07030, 2000.

Strabala, K. I., Ackerman, S. A., and Menzel, W. P.: Cloud properties inferred from 8-12- $\mu \mathrm{m}$ data, J. Appl. Meteorol., 33, 212229, 1994.
Turner, D. D.: Arctic mixed-phase cloud properties from AERI lidar observations: Algorithm and results from SHEBA, J. Appl. Meteorol., 44, 427-444, doi:10.1175/JAMC2208.1, 2005.

Turner, D. D., Ackerman, S. A., Baum, B. A., Revercomb, H. E., and Yang, P.: Cloud phase determination using ground-based AERI observations at SHEBA, J. Appl. Meteorol., 42, 701-715, doi:10.1175/1520-0450(2003)042<0701:CPDUGA>2.0.CO;2, 2003.

Uttal, T., Curry, J. A., Mcphee, M. G., Perovich, D. K., Moritz, R. E., Maslanik, J. A., Guest, P. S., Stern, H. L., Moore, J. A., Turenne, R., Heiberg, A., Serreze, M. C., Wylie, D. P., Persson, O. G., Paulson, C. A., Halle, C., Morison, J. H., Wheeler, P. A., Makshtas, A., Welch, H., Shupe, M. D., Intrieri, J. M., Stamnes, K., Lindsey, R. W., Pinkel, R., Pegau, W. S., Stanton, T. P., and Grenfeld, T. C.: Surface Heat Budget of the Arctic Ocean, B. Am. Meteorol. Soc., 83, 255-275, doi:10.1175/15200477(2002)083<0255:SHBOTA>2.3.CO;2, 2002.

Vavrus, S., Waliser, D., Schweiger, A., and Francis, J.: Simulations of 20th and 21st century Arctic cloud amount in the global climate models assessed in the IPCC AR4, Clim. Dynam., 33, 1099-1115, doi:10.1007/s00382-008-0475-6, 2009.

Verlinde, J., Harrington, J. Y., McFarquhar, G. M., Yannuzzi, V. T., Avramov, A., Greenberg, S., Johnson, N., Zhang, G., Poellot, M. R., Mather, J. H., Turner, D. D., Eloranta, E. W., Zak, B. D., Prenni, A. J., Daniel, J. S., Kok, G. L., Tobin, D. C., Holz, R., Sassen, K., Spangenberg, D., Minnis, P., Tooman, T. P., Ivey, M. D., Richardson, S. J., Bahrmann, C. P., Shupe, M., DeMott, P. J., Heymsfield, A. J., and Schofield, R.: The MixedPhase Arctic Cloud Experiment, B. Am. Meteorol. Soc., 88, 205221, doi:10.1175/BAMS-88-2-205, 2007.

Vogelmann, A. M., McFarquhar, G. M., Ogren, J. A., Turner, D. D., Comstock, J. M., Feingold, G., Long, C. N., Jonsson, H. H., Bucholtz, A., Collins, D. R., Diskin, G. S., Gerber, H., Lawson, R. P., Woods, R. K., Andrews, E., Yang, H.-J., Chiu, J. C., Hartsock, D., Hubbe, J. M., Lo, C., Marshak, A., Monroe, J. W., McFarlane, S. A., Schmid, B., Tomlinson, J. M., and Toto, T.: RACORO extended-term aircraft observations of boundary layer clouds, B. Am. Meteorol. Soc., 93, 861-878, doi:10.1175/BAMS-D-1100189.1, 2012.

Vömel, H., Selkirk, H., Miloshevich, L., Valvarde-Canossa, J., Vadés, Kyrö, E., Kivi, R., Stolz, W., Peng, G., and Diaz, J.A.: Radiation dry bias of the Vaisala RS92 humidity sensor, J. Atmos. Ocean Tech., 24, 953-963, doi:10.1175/JTECH2019.1, 2007.

Wang, X. and Key, J.: Arctic surface, cloud, and radiation properties based on the AVHRR Polar Pathfinder dataset. Part I: Spatial and temporal characteristics, J. Climate, 18, 2558-2574, doi:10.1175/JCLI3438.1, 2005.

Wiscombe, W. J.: Mie scattering calculations: Advances in technique and fast, vector-speed computer codes, NCAR Technical Note NCAR/TN-140+STR, National Center for Atmospheric Research, Boulder, CO, 1979.

Wiscombe, W. J.: Improved Mie scattering algorithms, Appl. Optics, 19, 1505-1509, doi:10.1364/AO.19.001505, 1980.

Yang, P., Wei, H., Huang, H.-L., Baum, B. A., Hu, Y. X., Kattawar, G. W., Mishchenko, M. I., and Fu, Q.: Scattering and absorption property database for nonspherical ice particles in the near- through far-infrared spectral region, Appl. Optics, 44, 5512-5523, doi:10.1364/AO.44.005512, 2005. 
Yang, P., Bi, L., Baum, B. A., Liou, K. N., Kattawar, G. W., Mishchenko, M. I., and Cole, B.: Spectrally Consistent Scattering, Absorption, and Polarization Properties of Atmospheric Ice Crystals at Wavelengths from 0.2 to $100 \mu \mathrm{m}$, J. Atmos. Sci., 70, 330-347, doi:10.1175/JAS-D-12-039.1, 2013.
Zhao, C., Xie, S., Klein, S. A., Protat, A., Shupe, M. D., McFarlane, S. A., Comstock, J. M., Delanoë, J., Deng, M., Dunn, M., Hogan, R. J., Huang, D., Jensen, M. P., Mace, G. G., McCoy, R., O'Connor, E. J., Turner, D. D., and Wang, Z.: Toward understanding of differences in current cloud retrievals of ARM ground-based measurements, J. Geophys. Res.-Atmos., 117, D10206, doi:10.1029/2011JD016792, 2012. 